\title{
Entrepreneurial Self-efficacy of Vocational and Technical Secondary School Students.
}

\begin{abstract}
Entrepreneurial self-efficacy of school students has been under investigation as one of the influential factors to ultimately become an entrepreneur. However, little is known about selfefficacy of technical and vocational schools to choose entrepreneurship as their future career path. In this study, entrepreneurial self-efficacy of vocational and technical secondary school students in central zone of Malaysia was identified through employing a survey method. Students' mean score for entrepreneurial self-efficacy is in the moderate to high level, ranging from 3.57 to 3.75 . For the Malay students, the mean score for developing new product and market opportunities, building an innovative environment, initiating investors relationship, defining core purposes as well as developing critical human resource were significantly higher compared to non-Malay students. The implications of the findings for policy makers and educators are discussed in this paper.
\end{abstract}

Keyword: Entrepreneurial Self-Efficacy; Vocational Students; Technical Students. 